\title{
Human capital differences in philanthropic vs. traditional venture capital firms
}

Mariarosa Scarlata, Jennifer M. Walske and Andrew Zacharakis

Published Online: 30 Nov 2017 |https://doi.org/10.5465/ambpp.2015.12458abstract

\section{Abstract}

Philanthropic venture capital (PhVC), like traditional venture capital (TVC), provides funding and value added services to a portfolio of entrepreneurial firms. However, TVC differs from PhVC as TVC's primary goal is to maximize the economic return of its investments. In contrast, PhVC firms expect their portfolio companies to perform well in terms of social and economic return. This paper is the first known work to compare the differences in human capital (HC) between PhVC and TVC firms, using hand-collected data. Our findings show that there are key differences in both general and specific HC between these firm types. PhVC firm founders have much greater social work experience, compared to founders of TVC firms. However, we also find that founders of both TVC and PhVC firms have high levels of commercial work experience. As for educational related variables, we find that TVC firm founders have significantly more education in science, engineering, business, and law. 

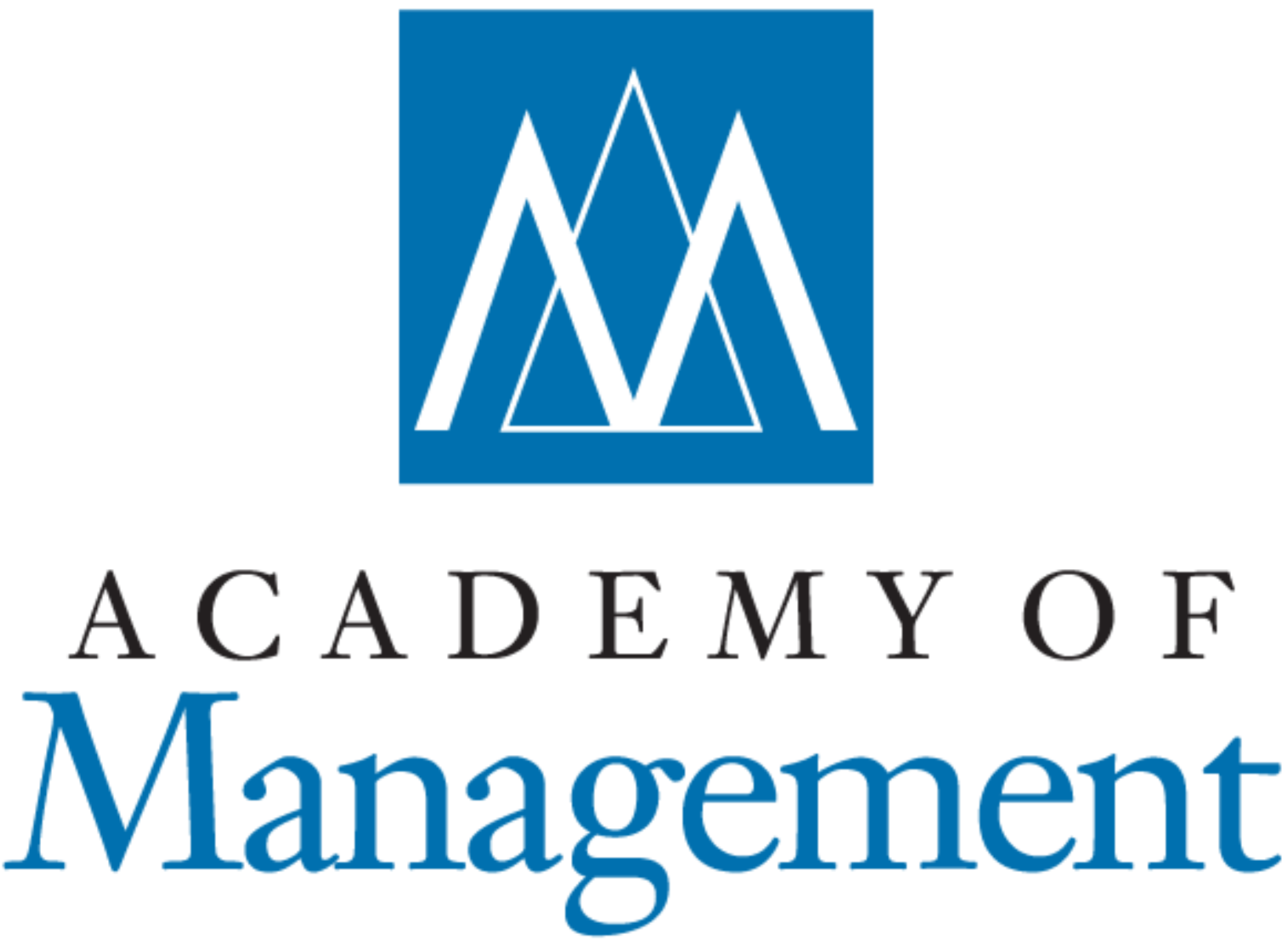

Academy of Management

555 Pleasantville Road, Suite N200

Briarcliff Manor, NY 10510-8020, USA

Phone: +1 (914) 326-1800

Fax: +1 (914) 326-1900

Privacy Policy Logo Use

(c) 2021 Academy of Management

Powered by Atypon ${ }^{\circledR}$ Literatum 